\title{
Pre-implantation and pre-annealing effects on deuterium retention in tungsten
}

\author{
O.V. Ogorodnikova, J. Roth, M. Mayer* \\ Max-Planck-Institut für Plasmaphysik, EURATOM-Association, Boltzmannstraße 2, 85748 Garching, \\ Germany
}

\begin{abstract}
Ion-driven deuterium retention in polycrystalline tungsten has been studied by thermodesorption spectroscopy as a function of the pre-implantation and pre-annealing treatments. Two kinds of tungsten samples were implanted by deuterium ions: (i) as-received $\mathrm{W}$ and (ii) re-crystallized W. Higher deuterium retention has been found for as-received W compared to re-crystallized. Pre-implantation by deuterium ions with intermediate TDS increases the deuterium retention. An increase of the deuterium retention with temperature at relatively high fluences was observed. The possible mechanisms of this behavior are discussed.
\end{abstract}

\footnotetext{
* Corresponding author: tel.: +49 893299 1639, e-mail: Matej.Mayer@ipp.mpg.de
} 


\section{Introduction}

Tungsten (W) is considered as plasma-facing material for long pulse burning plasma devices like ITER. Currently, it is foreseen to use tungsten only in the divertor region where ion energies are low, while for future fusion power reactors tungsten may be used also in the main chamber, where particle energies reach into the keV-range. The retention of low-energy $\mathrm{D}$ ions in $\mathrm{W}$ has been studied in several publications. However, the understanding of hydrogen trapping in tungsten as a function of fluence, impurity content, temperature and material structure has not yet reached a level for precise predictions of hydrogen isotopes inventory under ITER conditions. Despite of the similarities with low-energy deuterium irradiation at room temperature, the saturation values of deuterium retention were scattered as $6 \times 10^{20} \mathrm{D} / \mathrm{m}^{2}$ at a fluence of about $F=1 \times 10^{23} \mathrm{D} / \mathrm{m}^{2}[1,2], 2 \times 10^{21} \mathrm{D} / \mathrm{m}^{2}$ at a fluence above $F=5 \times 10^{22} \mathrm{D} / \mathrm{m}^{2}$ [3] , and $2 \times 10^{21} \mathrm{D} / \mathrm{m}^{2}$ at a fluence above $F=4 \times 10^{24} \mathrm{D} / \mathrm{m}^{2}$ [4]. Both papers [1] and [4] reported that polycrystalline W (PCW) samples did not saturate in retention for the high temperatures of 400$500 \mathrm{~K}$ up to a fluence of $F=5 \times 10^{24} \mathrm{D} / \mathrm{m}^{2}$. However, the deuterium retention was reported to be $2 \times 10^{21} \mathrm{D} / \mathrm{m}^{2}$ in [1] at $T=500 \mathrm{~K}$ and $4 \times 10^{20} \mathrm{D} / \mathrm{m}^{2}$ in [4] at $T=470 \mathrm{~K}$ at a fluence of about $F=4 \times 10^{24} \mathrm{D} / \mathrm{m}^{2}$. Currently, there is no explanation for this difference of one order of magnitude in the deuterium (D) retention under the similar experimental conditions. However, it became clear that differences in the tungsten preparation, in tungsten structure, impurity content and pre-implantation history could essentially effect deuterium retention in W. This paper focuses on the influence of the pre-irradiation treatment of the $\mathrm{W}$ samples and pre-implantation effects on deuterium diffusion and trapping under low- and high-energy deuterium implantation. Possible mechanisms of different deuterium behavior in un-annealed and pre-annealed PCW are discussed.

\section{Experimental}




\subsection{Specimen preparation}

Polycrystalline tungsten (PCW) samples manufactured by Plansee with a purity of $99.999 \%$ were used. This material is proposed for ITER. The dimensions of the samples were $12 \times 15 \times 0.5 \mathrm{~mm}^{3}$. The grain sizes were estimated to be in the range of 5-20 $\mu \mathrm{m}$. All specimens were mechanically polished and outgased at $1273 \mathrm{~K}$ for 20 minutes in the implantation chamber at a background pressure of $10^{-6} \mathrm{~Pa}$. Some samples were electro-polished, and some samples were annealed at $\mathrm{T}=1573 \mathrm{~K}$ for three hours in vacuum with a background pressure of $2 \times 10^{-4} \mathrm{~Pa}$ before implantation. This temperature is high enough to remove any electro-polish residue from the surface, as well as some impurities, vacancies and dislocations in the near-surface layer and to reduce the concentration of dislocations and grain boundaries in the bulk. The purpose of annealing above the re-crystallization temperature was to get reproducible results.

\subsection{Deuterium implantation and TDS}

The retention of deuterium implanted into polycrystalline tungsten was investigated by thermal desorption spectroscopy (TDS) after implantation using a linear heating ramp. The released particles $\mathrm{H}_{2}, \mathrm{HD}$ and $\mathrm{D}_{2}$ were detected with a Balzers 511 quadrupole mass spectrometer (QMS). To reduce the background level (especially of $\mathrm{H}_{2} \mathrm{O}$ ), the quadrupole ion source is separately pumped and surrounded by a liquid nitrogen cooled copper shield. Deuterium implantation and TDS measurements were performed at the Garching high current source using $\mathrm{D}_{3}{ }^{+}$ions at normal incidence to the test specimen [4,5]. The ion flux density was between $2.5 \times 10^{19}$ and $8 \times 10^{19} \mathrm{D} / \mathrm{m}^{2} \mathrm{~s}$.

\section{Results and discussion}

Fig. 1 shows the $\mathrm{D}$ retention in $\mathrm{PCW}$ as a function of implantation fluence, $F$, for $200 \mathrm{eV}$ deuterium implantation at room temperature and at elevated temperatures ranging from $380 \mathrm{~K}$ to 
$470 \mathrm{~K}$. For room temperature, a slightly higher D retention was detected for as-received $\mathrm{W}$ than for pre-annealed $\mathrm{W}$. The D retention increases somewhat faster than the square root of fluence at room temperature, as $\sim F^{0.7}$. Increasing the temperature results in a reduction of the amount of retained $\mathrm{D}$ in pre-annealed $\mathrm{W}$ up to a fluence of $F=10^{24} \mathrm{D} / \mathrm{m}^{2}$. The same tendency was found for energetic ions implantation at $3 \mathrm{keV}$ : the deuterium retention decreases with increasing implantation temperature for pre-annealed samples (Fig. 2). However, D retention increases faster with fluence for elevated temperatures (400-500 K) compared to moderate temperatures of $300-373 \mathrm{~K}$. It seems that $\mathrm{D}$ retention at $400-500 \mathrm{~K}$ is higher than at $300-373 \mathrm{~K}$ at such high fluences as $F>5 \times 10^{24} \mathrm{D} / \mathrm{m}^{2}$. A similar tendency of increasing D inventory at high irradiation temperatures even at lower fluences was observed in [1] by implanting $1 \mathrm{keV}$ deuterium ions in multiple-used W specimens. A possible explanation is, that increasing the temperature enhances the $\mathrm{D}$ agglomeration in bubbles due to the higher mobility of deuterium atoms and vacancies.

Fig. 3 shows thermo-desorption spectra after the implantation of $3 \mathrm{keV} \mathrm{D}^{+}$in un-annealed and pre-annealed tungsten. The D retention in un-annealed $\mathrm{W}$ is two times higher than in preannealed W (see Fig. 2). Moreover, the amount of D increases in the high-temperature traps. In general, annealing results in a reduction of the total amount of D in W [4]. For low temperature irradiation in the range of 300-400 K, TDS spectra with a linear heating ramp of $8 \mathrm{~K} / \mathrm{s}$ show two peaks [4]: a low-temperature peak which was associated with atomic deuterium trapping in dislocations, grain boundaries, etc., and a high-temperature peak which corresponds to deuterium agglomeration in bubbles and trapping in vacancies. Low-energy traps have a trap energy of 0.85 $\mathrm{eV}$, and high-temperature traps $1.45 \mathrm{eV}$. The retention in the first peak decreases with increasing temperature because the low-temperature traps cannot hold the deuterium. Deuterium can be either easily released or re-trapped in high-temperature defects. The deuterium content in hightemperature defects is higher for un-annealed W than for re-crystallized W. Calculations using the model in [4] confirm that the amount of ion-induced $1.45 \mathrm{eV}$ traps is higher for un-annealed 
W compared to re-crystallized W. This means that both the initial concentration of intrinsic vacancies and the rate of bubble growth are higher in $\mathrm{W}$ without a pre-heating treatment. Most probably, the bubble growth is more pronounced for un-annealed $\mathrm{W}$ due to the pre-existence of a higher amount of intrinsic traps (grain boundaries, dislocations and impurities), which can be nucleation sites for D clustering.

Scanning electron micrographs (SEM) shows, that blisters produced by energetic ions have a larger size in un-annealed $\mathrm{W}(\sim 3 \mu \mathrm{m})$ than in re-crystallized $\mathrm{W}(\sim 1-2 \mu \mathrm{m})$ (Fig. 4). The high temperature strength and strain of tungsten depend on the annealing treatment and may change significantly at certain temperatures. Since re-crystallized W has less strength and higher ductility than as-received $\mathrm{W}$, the stresses arising during implantation can more easily relax in recrystallized W than in un-annealed, cold-worked W.

The implantation history of the sample indeed influences the D retention in $\mathrm{W}$ [1]. The first irradiation on the sample always results in the lowest retention rate. The $\mathrm{D}$ retention rate rises with cumulative fluence. TDS measurements show, that the pre-irradiation of $\mathrm{W}$ by energetic ions with intermediate heating up to $1373 \mathrm{~K}$ enhances the growth of the high-temperature peak (Fig. 5). It means that the density of $1.45 \mathrm{eV}$ traps strongly increases after long implantation of energetic deuterium ions and subsequent heating.

It was found in [6] that ion-induced traps do not anneal up to T>1700 K. During TDS, D was released from the traps but the traps themselves are still in the implantation range. Thus, multiple use of a sample for several experimental campaigns and subsequent TDS results in an increase of the concentration of vacancies and vacancy clusters near the surface.

Calculations using a diffusion model with low-energy 'natural' defects distributed over the whole thickness of the sample, and high-energy 'ion-induced' defects distributed near the implantation surface and growing during the implantation, describe well the experimental data for $200 \mathrm{eV} \mathrm{D}^{+}$[4]. The increase of the trap density, $W$, with fluence can be written as follows 
$W(x, t)=W_{m}\left(1-\exp \left(-(1-r) I_{0} \psi(x) \eta t / W_{m}\right)\right)$,

where $I_{0}$ is the incident flux, $r$ is the reflection coefficient, $\psi$ is the depth distribution of ioninduced defects, $\eta$ is the rate of the defect creation and $W_{m}$ is the maximal defect concentration. Calculations using a high rate, $\eta$, of production of $1.45 \mathrm{eV}$ traps in the case of pre-implantation show a good agreement with experiments (Fig. 5). This is an evidence that previous irradiation followed by intermediate TDS increases D clustering and bubble formation.

An increase of irradiation temperature (Fig. 6) results in

- a reduction or disappearance of the $\mathrm{D}$ retention in $450 \mathrm{~K}$ trap sites for both pre-heated $\mathrm{W}$ and as-received $\mathrm{W}$,

- a reduction of the D retention in the high-temperature peak for re-crystallized W (Fig. 6a),

- an increase of the D retention in high-temperature traps of $1.45 \mathrm{eV}$ for $\mathrm{W}$ pre-implanted by deuterium ions (Fig. 6b).

This strong temperature dependence of deuterium retention with the pre-implantation history can be explained by the presence of additional high-energy traps after long irradiation, which are not annealed away during TDS. The annealing can even accelerate the creation of hightemperature traps. The pre-existence of a high concentration of $1.45 \mathrm{eV}$ traps creates conditions with enhanced rate of bubble formation, especially at high temperatures when the mobility of vacancies and deuterium increases. Taking the higher rate of ion-induced defect formation for re-used samples into account, good agreement between experiments and calculations can be achieved (Fig. 6).

The increase of the D inventory with temperature could be also attributed to the presence of a high surface barrier for recombination. However, there is no convincing physical explanation for an increase of the surface barrier during repetitive cycling of irradiation and heating. One could suggest that impurities are deposited on the W surface during TDS and create this barrier. 
However, impurities should be sputtered away during the long-time implantation with high fluences.

Fig. 7 illustrates the dependence of the $\mathrm{D}$ retention on the irradiation temperature. The D retention decreases monotonously with temperature for 'virgin' $\mathrm{W}$ at a fluence of $10^{23} \mathrm{D} / \mathrm{m}^{2}$, while complicated temperature dependence with a maximum at about $450 \mathrm{~K}$ is observed for multiple-used $\mathrm{W}$ at the same fluence. A similar temperature dependence with a maximum is also observed for 'virgin' tungsten sample but at higher incident fluences $>10^{25} \mathrm{D} / \mathrm{m}^{2}$. This means that the fluence threshold for bubble growth reduces with both un-annealed W and re-used W for several implantation campaigns with intermediate TDS.

\section{Summary}

Deuterium retention in polycrystalline $\mathrm{W}$ was studied in dependence of $\mathrm{W}$ pre-annealing and sample irradiation history. Pre-annealing of $\mathrm{W}$ and the irradiation history do influence the D retention in W. Pre-annealing reduces the amount of dislocations, grain boundaries and, consequently, decreases the $\mathrm{D}$ retention. A higher concentration of initial intrinsic defects increases the rate of ion-induced defects production during implantation. The concentration of high-temperature traps is higher for un-annealed $\mathrm{W}$ compared to pre-annealed $\mathrm{W}$.

Pre-implantation effects, such as multiple use of the same sample for several irradiation campaigns with intermediate TDS, result in an increase of the density of initial high-temperature traps and, thus, accelerate the bubble growth. Consequently, pre-implantation reduces the fluence threshold for bubble formation. The following conclusions can be made:

- Pre-annealing at $1573 \mathrm{~K}$ for three hours prevents a fast growth of the high-temperature traps of $1.45 \mathrm{eV}$ with fluence and reduces the growth of blisters for high-energy deuterium ions irradiation.

- The D retention in re-crystallized $\mathrm{W}$ is less than in as-received $\mathrm{W}$. 
- There are conditions, where the D retention can increase with temperature. Namely, the $\mathrm{D}$ retention in low-temperature traps of $0.85 \mathrm{eV}$ decreases, but it increases in hightemperature trapping sites of $1.45 \mathrm{eV}$. This temperature effect depends on the preimplantation history, annealing treatment, fluence and flux.

- Previous irradiation enhances the D trapping in the $1.45 \mathrm{eV}$ defects. This means that the re-use of $\mathrm{W}$ for several experiments increases the rate of deuterium cluster formation.

- The fluence threshold for bubble growth increases with pre-annealing and reduces with pre-implantation by energetic deuterium ions with intermediate TDS.

Tungsten is foreseen to be used at temperatures higher than $500 \mathrm{~K}$ in ITER. ELM's and offnormal events may increase the rate of ion-induced defect production. Irradiation by fast neutrons will create vacancies over the whole $\mathrm{W}$ thickness. Consequently, the deuterium retention in the $1.45 \mathrm{eV}$ traps will increase. In order to estimate in detail the $\mathrm{D}$ retention in $\mathrm{W}$ plasma-facing components, the detailed exposure history in ITER has to be taken into account. 


\section{Acknowledgement}

We would like to thank A. Weghorn for technical assistance and S. Lindig for SEM investigations. 


\section{References}

[1] A.A. Haasz, J.W. Davis, M. Poon, R.G. Macaulay-Newcombe, J. Nucl. Mater. 258-263 (1998) 889.

[2] M. Poon, J.W. Davis, A.A. Haasz, J. Nucl. Mater. 283-287 (2000) 1062.

[3] V.Kh. Alimov, B.M.U. Scherzer, J. Nucl. Mater. 240 (1996) 75.

[4] O.V. Ogorodnikova, J. Roth, M. Mayer, J. Nucl. Mater. 313-316 (2003) 469.

[5] W. Eckstein, C. Garcia-Rosales, J. Roth and W. Ottenberger, Max-Planck-Institut fuer Plasmaphysik, Sputtering data, Techn. Rept. IPP 9/82, 1993.

[6] H. Eleveld and A. van Veen, J. Nucl. Mater. 212-215 (1994) 1421.

[7] W. Eckstein, Computer simulation of ion-solid interaction, Springer Berlin 1991. 


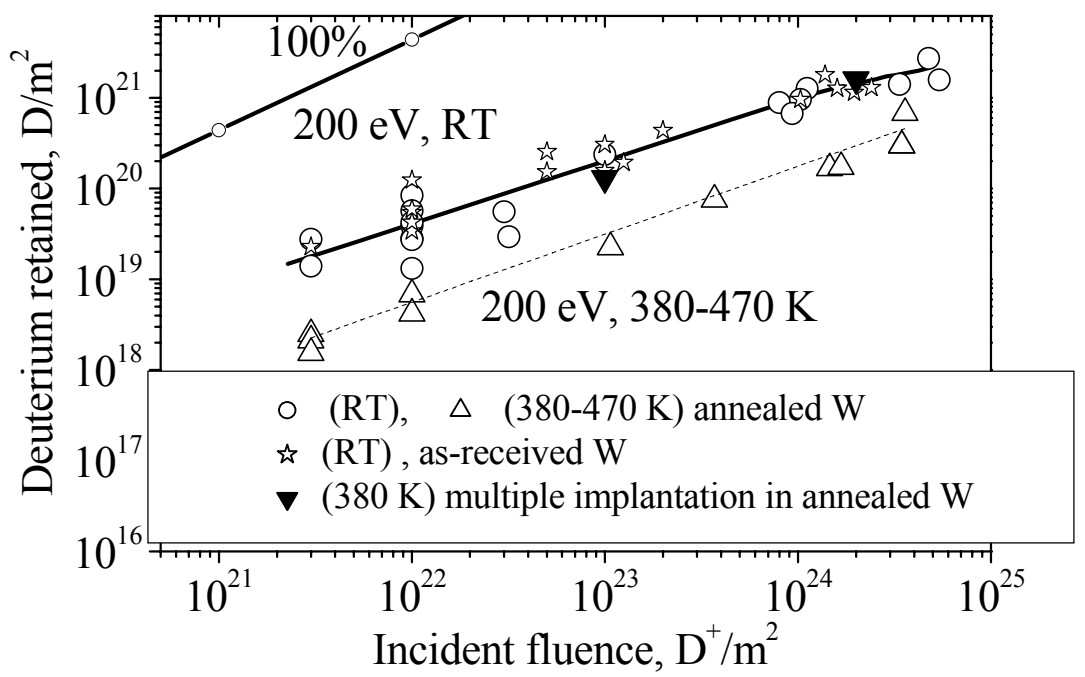

Fig. 1. Fluence dependence of the amount of retained deuterium in PCW pre-annealed at $\mathrm{T}=1573 \mathrm{~K}$ for 3 hours, and in as-received $\mathrm{PCW}$ after the implantation of $200 \mathrm{eV} \mathrm{D}^{+}$. The reflection coefficient of $200 \mathrm{eV} \mathrm{D}^{+}$from tungsten is $r=0.56$ [7]. 


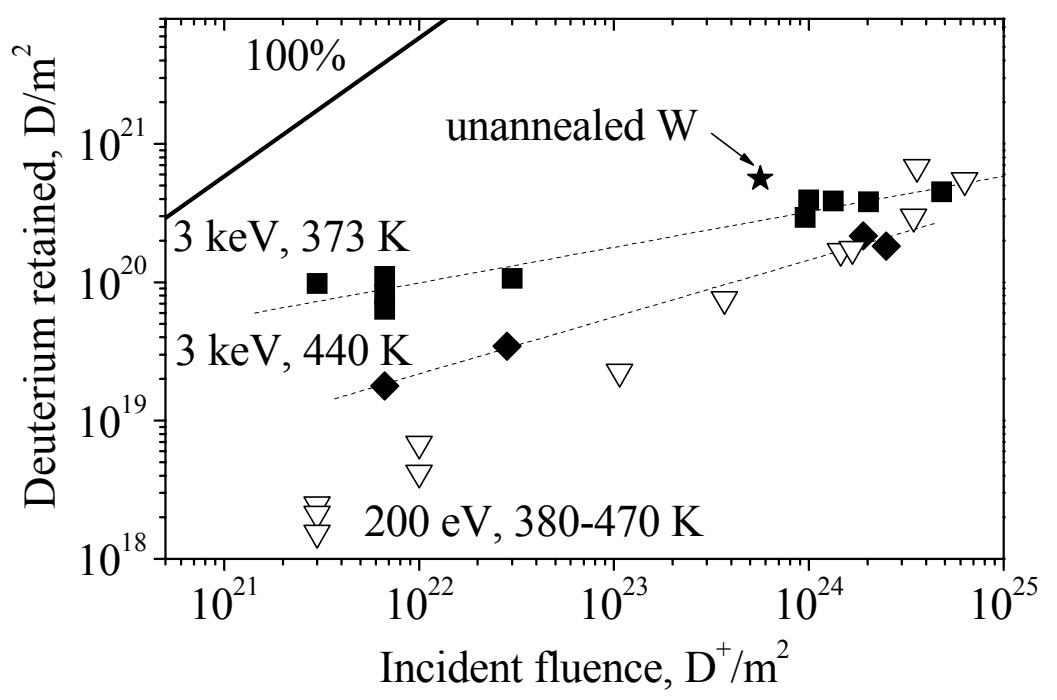

Fig. 2. Fluence dependence of the amount of retained deuterium in PCW pre-annealed at $\mathrm{T}=1573 \mathrm{~K}$ for 3 hours, and in as-received $\mathrm{PCW}$ after the implantation of $3 \mathrm{keV} \mathrm{D}$. The reflection coefficient of $3 \mathrm{keV} \mathrm{D}$ from tungsten is $r=0.417$ [7]. The deuterium retention in $\mathrm{W}$ irradiated by $200 \mathrm{eV} \mathrm{D}^{+}$at elevated temperatures in the range of $380-470 \mathrm{~K}$ is also shown for comparison. 


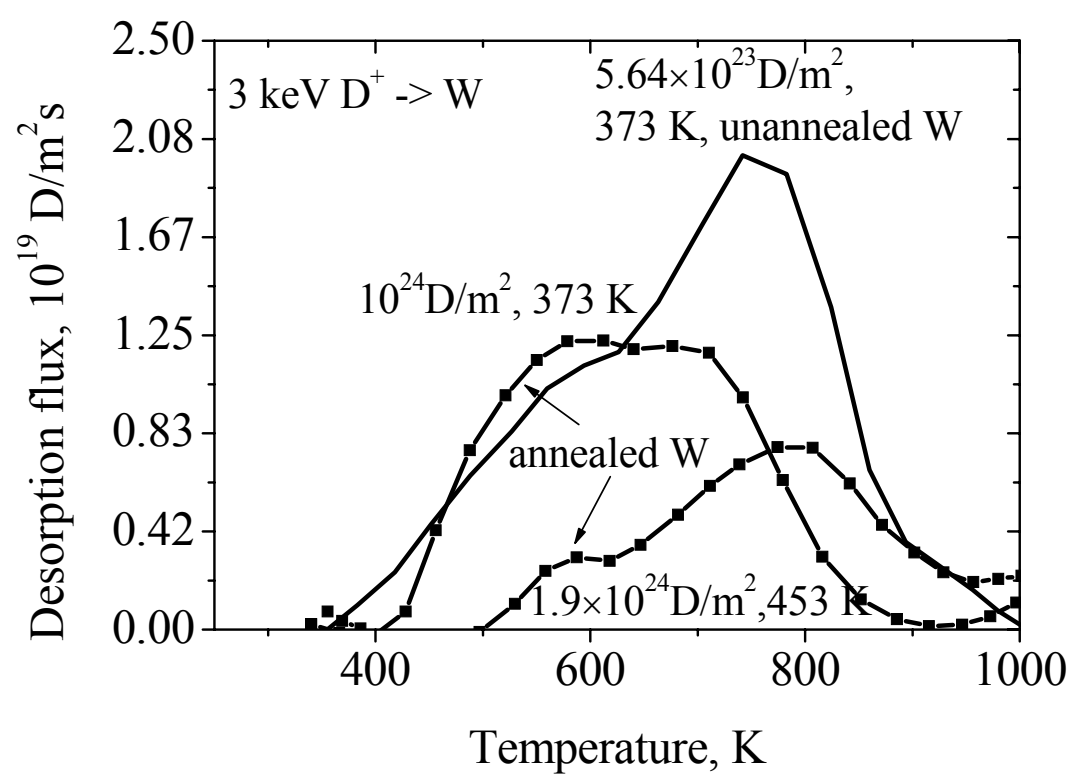

Fig. 3. Experimental thermodesorption spectra of deuterium from polycrystalline $\mathrm{W}$ irradiated by $3 \mathrm{keV} \mathrm{\textrm {D } ^ { + }}$ for pre-annealed $\mathrm{W}$ and un-annealed $\mathrm{W}$. 
a)

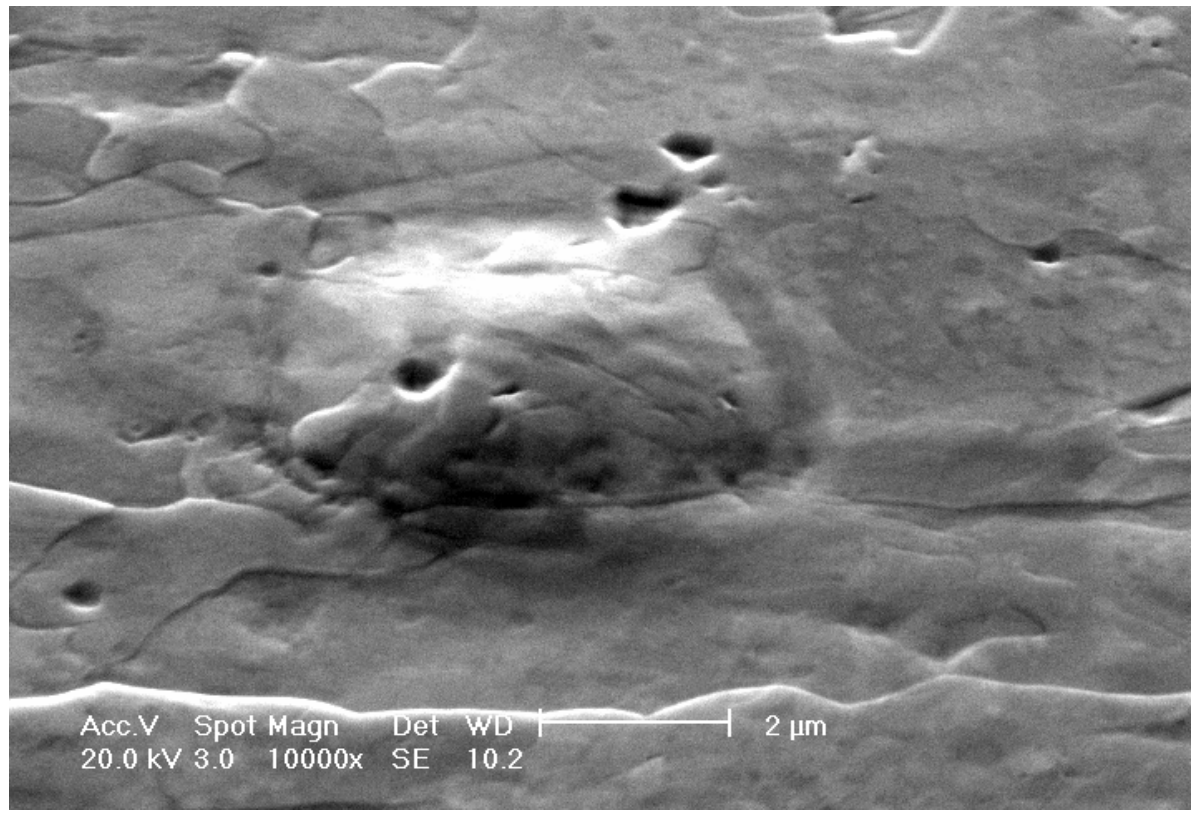

b)

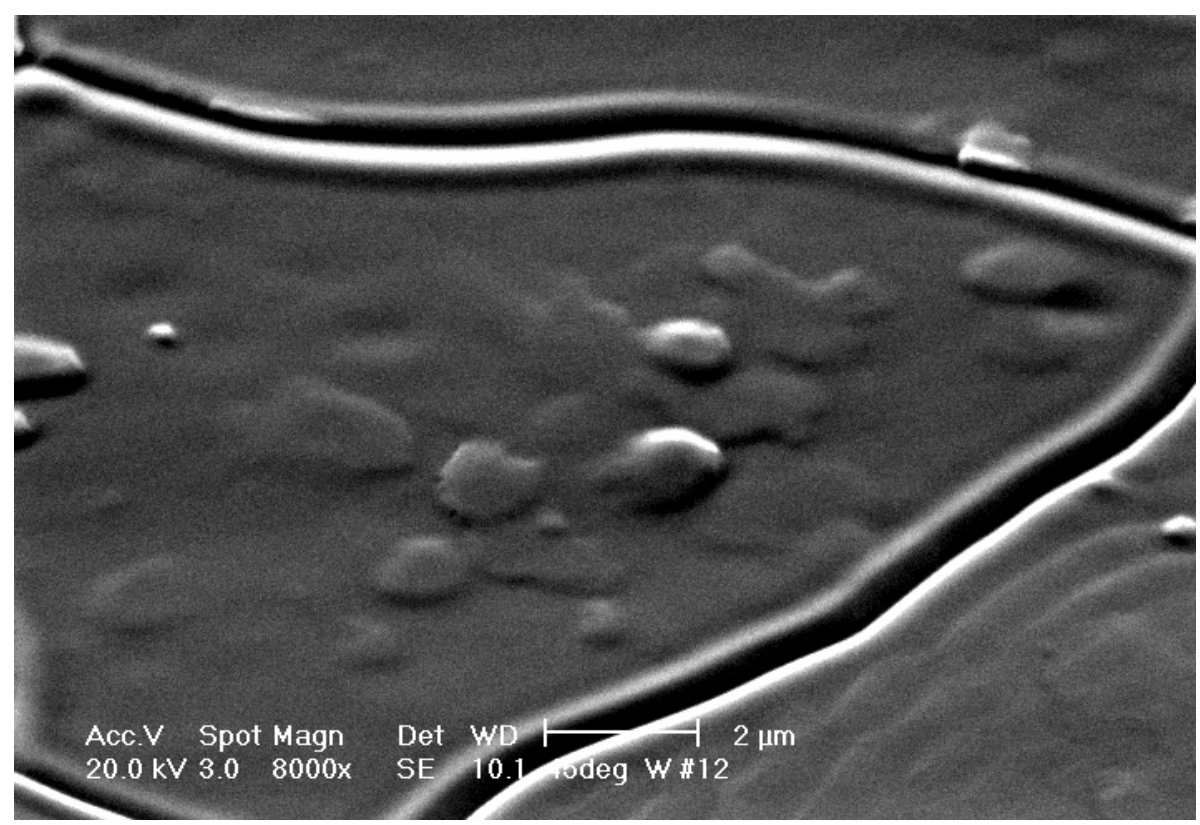

Fig. 4. SEM images of the surface of PCW irradiated by $3 \mathrm{keV} \mathrm{D}{ }^{+}$. The images were done after TDS.

a) Un-annealed PCW irradiated by $3 \mathrm{keV} \mathrm{D}^{+}$at $\mathrm{RT}$ (373 $\mathrm{K}$ during implantation) up to a fluence of $5.64 \times 10^{23} \mathrm{D} / \mathrm{m}^{2}$.

b) Pre-annealed PCW at $1573 \mathrm{~K}$ for 3 hours, and irradiated by $3 \mathrm{keV} \mathrm{D}{ }^{+}$at RT (373 K during implantation) up to a fluence of $1.34 \times 10^{24} \mathrm{D} / \mathrm{m}^{2}$, then by $200 \mathrm{eV} \mathrm{D}$ at RT up to a fluence of $1.8 \times 10^{24} \mathrm{D} / \mathrm{m}^{2}$ with intermediate TDS. 


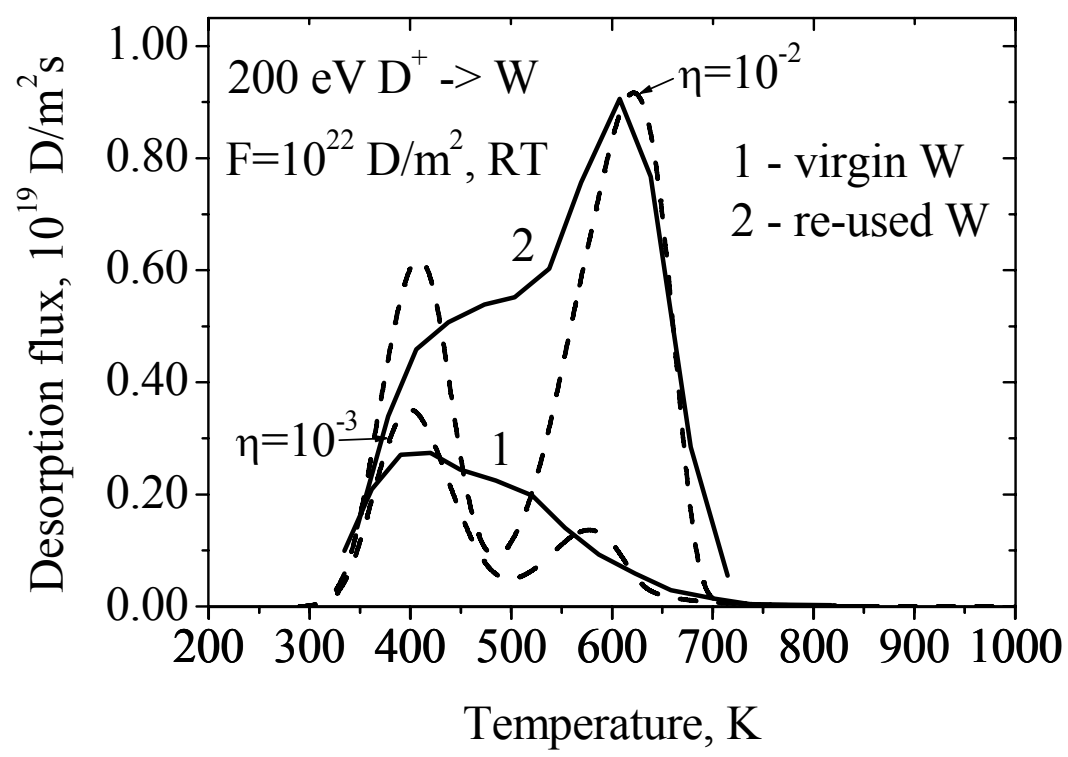

Fig. 5. Experimental thermodesorption spectra (solid lines) of deuterium from pre-annealed PCW irradiated by $200 \mathrm{eV}$ deuterium ions: (1) virgin sample, and (2) re-used sample after implantation of $3 \mathrm{keV} \mathrm{D}$ up to a fluence of $10^{24} \mathrm{D} / \mathrm{m}^{2}$. The fluence was $10^{22} \mathrm{D} / \mathrm{m}^{2}$ and the irradiation temperature was $300 \mathrm{~K}$. Calculations (dashed lines) using the higher rate of defect production for pre-implanted samples are in a good agreement with experiments. pis the rate of defect production. 


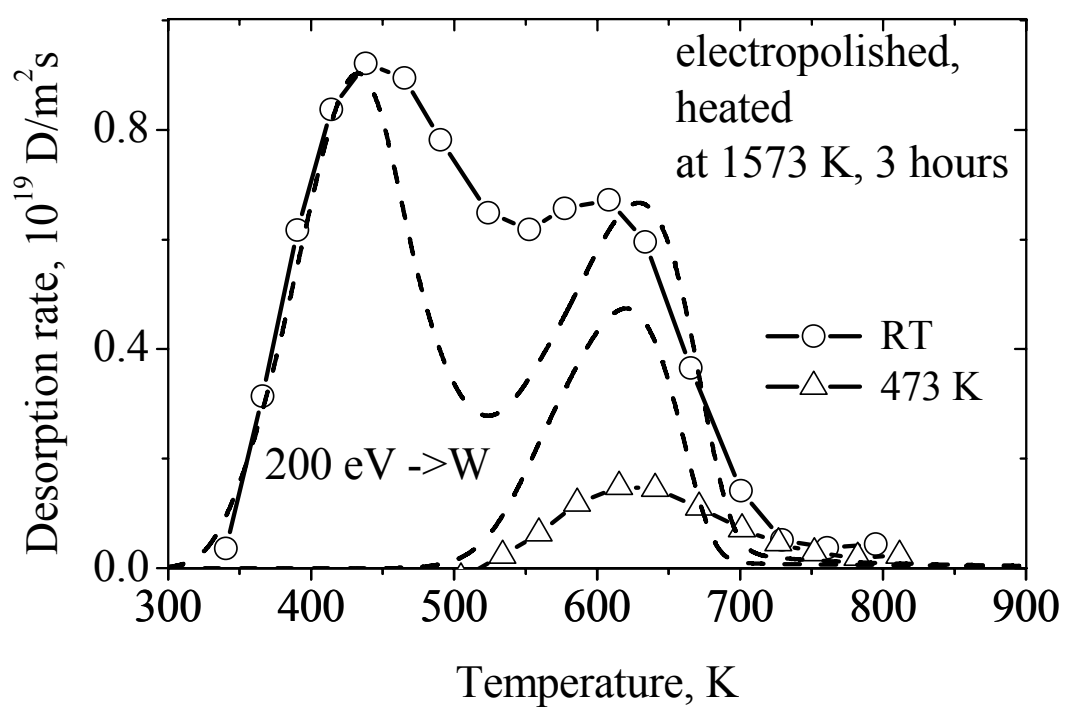

a)

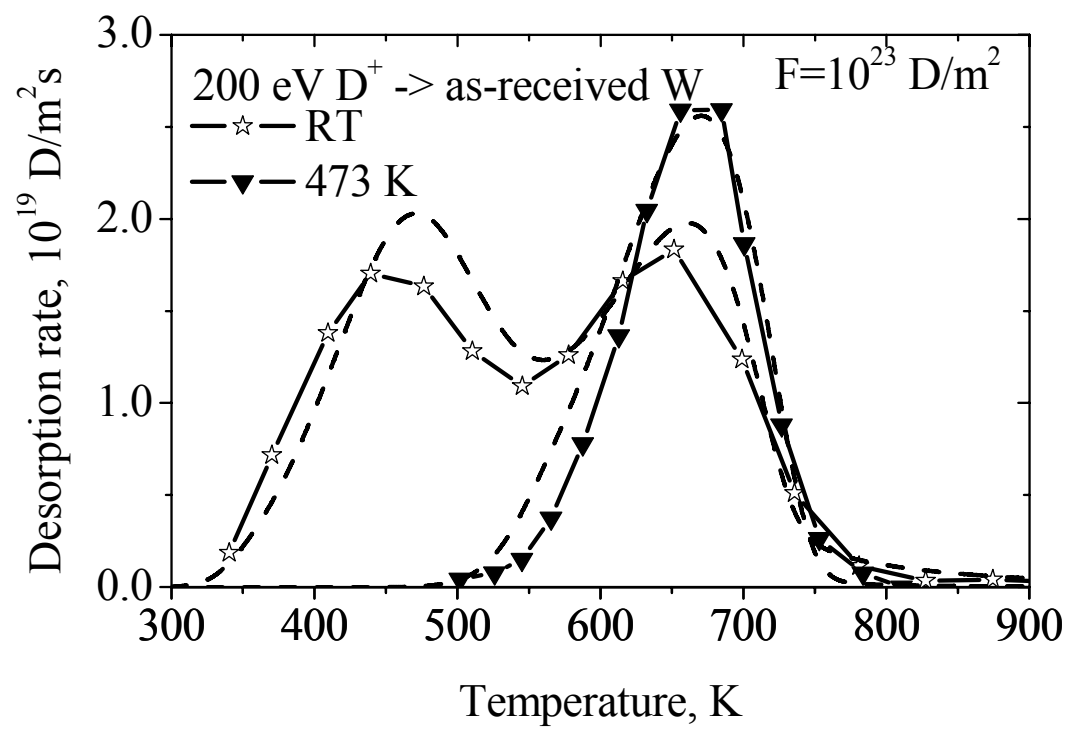

b)

Fig. 6. Experimental thermodesorption spectra (solid lines) of deuterium in PCW irradiated by $200 \mathrm{eV}$ deuterium ions. The fluence was $10^{23} \mathrm{D} / \mathrm{m}^{2}$ and the temperatures were $300 \mathrm{~K}$ and $473 \mathrm{~K}$. Calculations (dashed lines) using the higher rate of defect production for re-used samples are in good agreement with experiments.

a) $\mathrm{W}$ pre-annealed at $1573 \mathrm{~K}$ for three hours.

b) As-received $\mathrm{W}$ after multiple implantations. 


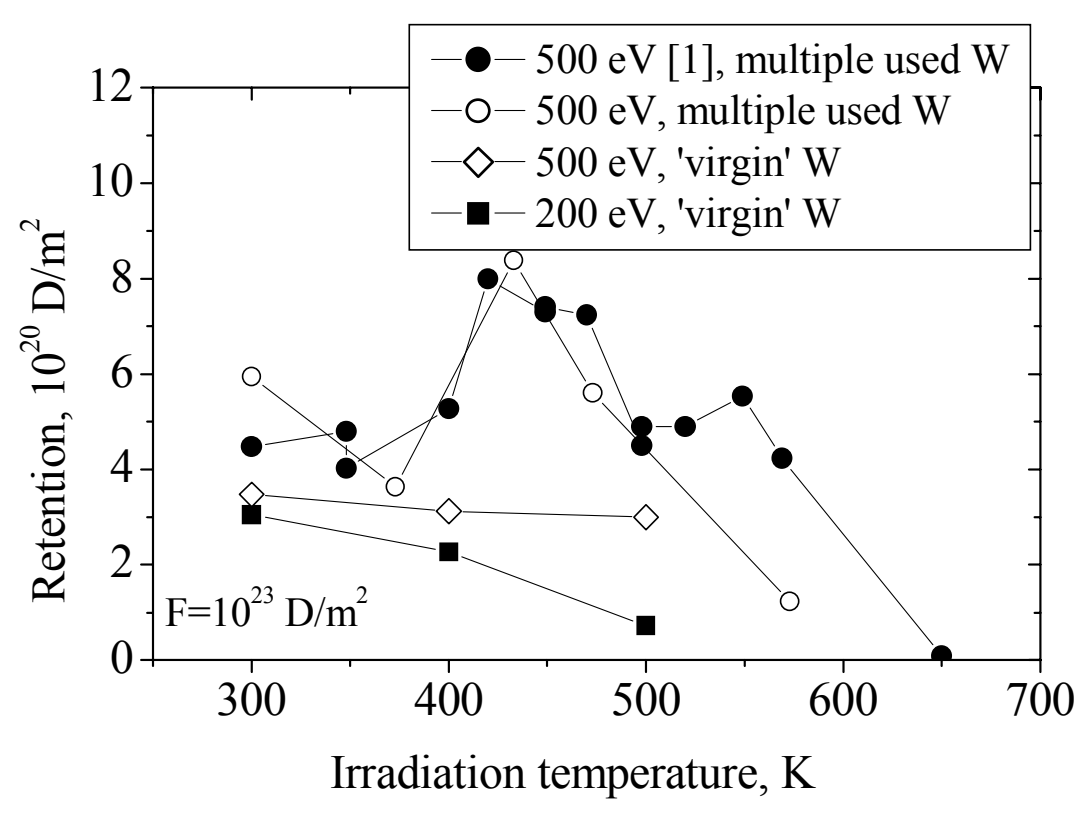

Fig. 7. Deuterium retention in 'virgin' polycrystalline $\mathrm{W}$ and in re-used $\mathrm{W}$ at a fluence of $10^{23} \mathrm{D} / \mathrm{m}^{2}$ as a function of irradiation temperature. 